\title{
A foreign body aspiration - plant or animal?
}

\author{
Pujitha Wickramasinghe $^{1}$, R Ajanthan ${ }^{2}$, Sanath P Lamabadusuriya ${ }^{3}$, M Sambasivam ${ }^{4}$
}

Sri Lanka Journal of Child Health, 2002; 31: 94-6

(Key words: foreign body aspiration)

\section{Introduction}

Foreign body aspiration in the tracheobronchial tree is a common paediatric emergency. It constitutes a significant cause of morbidity and mortality in the paediatric age group. Diagnosis is often delayed with symptoms and signs being attributed to other causes of respiratory distress. Food items, especially peanuts, are most commonly aspirated in infants and toddlers, whereas older children are more likely to aspirate non-food items such as pen caps, pins and paper clips ${ }^{1}$. Laryngeal impaction of a foreign body is very rare as most pass through the laryngeal inlet and get lodged lower down in the airway ${ }^{2}$.

\section{Case report}

A sixteen month old boy from Kadawatha presented with cough and fever of one day duration. The symptoms had started the previous evening when he had developed a mild cough while playing in the garden. A few hours later, he developed fever and wheezing and was treated by a general practitioner.

The next morning, as symptoms were not improving, he was brought to the Lady Ridgeway Hospital, where he was nebulised in the out patients department, and sent home. As they reached home, they decided to return as he was becoming more dyspnoeic.

On admission, he had a mild temperature of $99.4^{\circ} \mathrm{F}$, dyspnoea with an oxygen saturation of $75 \%$ on room air, which increased to $85 \%$ on 5 litres of $\mathrm{O}_{2}$ via nasal prongs. Air entry on left side of chest was reduced and chest radiograph showed a collapsed left lung (Figure 1).

Over the next few hours, the clinical condition deteriorated further. With the oxygen saturation dropping to $70 \%$, both the respiratory rate and heart rate increased and he became more and more restless.

${ }^{1}$ Lecturer, ${ }^{2}$ Senior Lecturer, ${ }^{3}$ Senior Professor, Department of Paediatrics, Faculty of Medicine, University of Colombo. ${ }^{4}$ House officer, Professorial Paediatric Unit, Lady Ridgeway Hospital, Colombo.

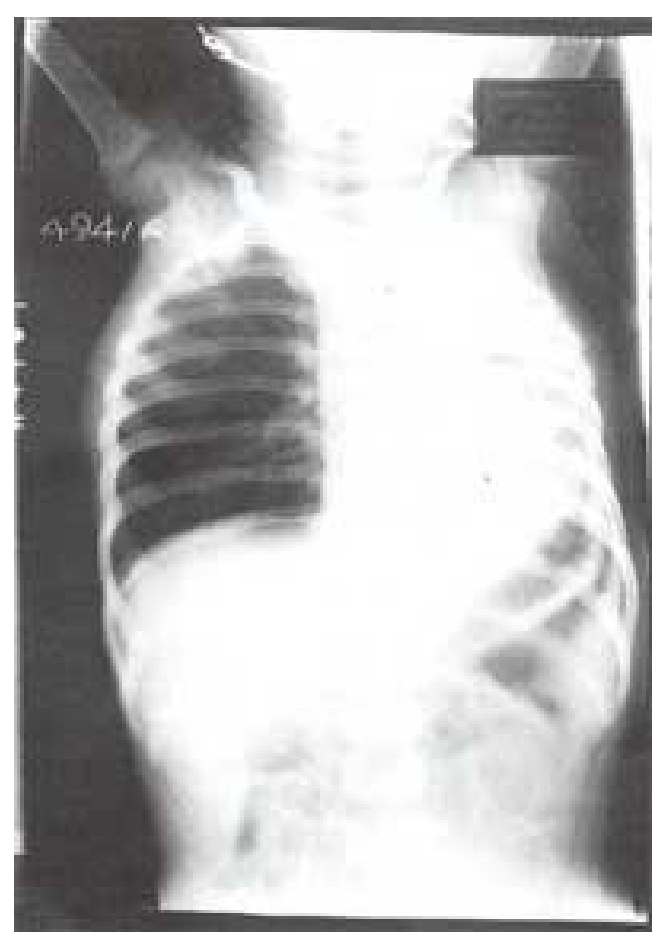

Figure 1

Though the clinical history was not typical of a foreign body inhalation, in consultation with the ENT surgeon, it was decided to subject the child to an emergency bronchoscopic examination.

Bronchoscopy under general anaesthesia revealed a normal larynx; thick purulent secretions were seen in both main bronchi, with slough in the left main bronchus. The secretions were aspirated. Several attempts were made to remove the necrotic material, but failed, as it was very fragile. The mucosa was oedematous and no foreign body was seen. The child was transferred to the intensive care unit for observation with the endotracheal tube (ET) in situ, to assist aspiration of secretions. He was not ventilated but managed with high flow $\mathrm{O}_{2}$ via the ET tube. Cefotaxime, cloxacillin and metronidazole were given intravenously in addition to an aminophylline infusion. 
The following morning, intensive chest physiotherapy was given and secretions sucked out. With the thick secretions, a white coloured mass was extruded, which was a foreign body (Figure 2). Within minutes, air entry in the left lung improved, with evidence of expansion of lung in the chest x-ray (Figure 3). He recovered completely and was discharged 2 days later.

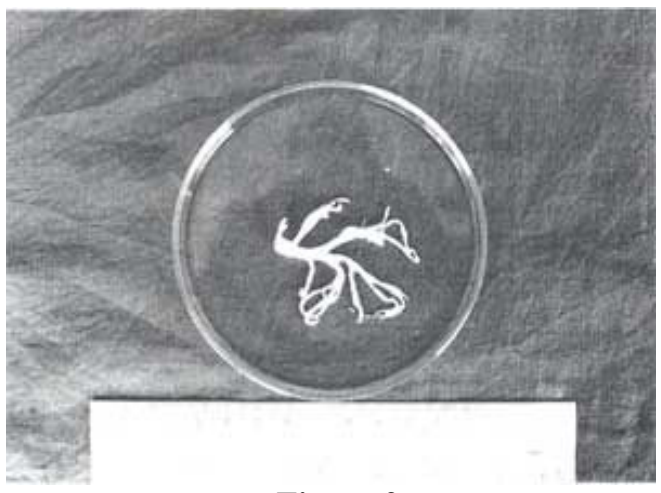

Figure 2

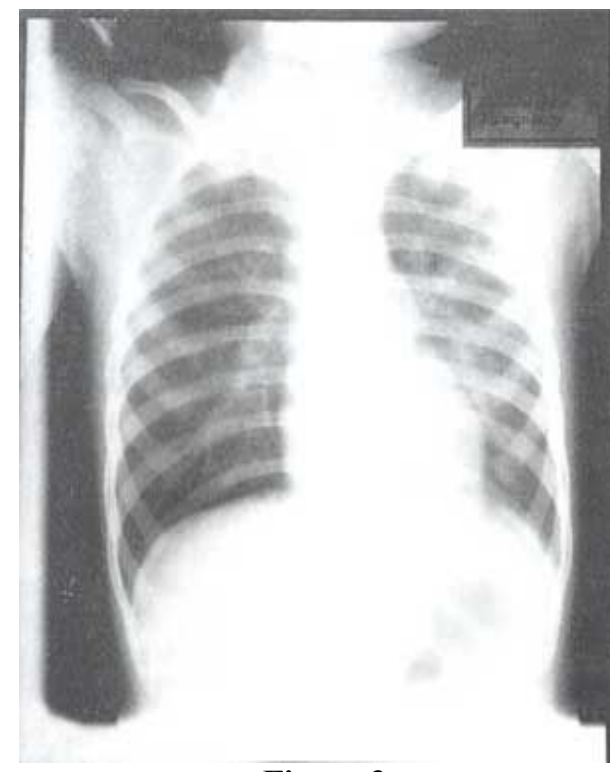

Figure 3

\section{Discussion}

Foreign body aspiration typically occurs in children and manifest as obstructive lobar or segmental over inflation or atelectasis. A high degree of suspicion is required to diagnose foreign body aspiration. A history of a witnessed choking episode is most important in early diagnosis. An asymptomatic period is common after aspiration and contributes to a delay in diagnosis of greater than one week in $12-26 \%$ of patients ${ }^{1}$. The danger of leaving behind infectious material is that, it will manifest later as necrotising consolidation and abscess formation ${ }^{3,4}$.

A child who presents with sudden onset cough and wheezing should always be treated with a high degree of suspicion for foreign body aspiration. History, physical examination and radiographic evaluation, performed in time, can lead to successful removal of a foreign body. On suspicion, a bronchoscopy should be considered even if there is no definite history of aspiration ${ }^{5}$.

In our patient, though the illness had started within 24 hours of admission, the degree of respiratory distress could not be explained by other pathological phenomena. The white colour of this foreign body resembled an exudate with necrotic tissue and its fragile nature did not permit removal via the bronchoscopic forceps as it broke into pieces at bronchoscopy.

The retrieved foreign body resembled the head of a cuttlefish. Assistance of the department of Zoology of University of Colombo was sought for identification and it was found to be of plant origin rather than of animal origin. The department of Botany of the same institute identified it as a fungus belonging to the family Clavariaceae. About 500 species belong to this family and many of the larger fleshy forms are edible ${ }^{6}$. The plant, which was aspirated, is of a non-edible form. It grows to few centimetres in height and is of various colours. These grow on the ground. Parents could not recall seeing such a plant in their garden and a subsequent search by one of the authors also could not trace a source. Probably it may have been foreign to their garden where the child picked up while playing.

More attention should be paid to obtaining a careful history and the use of radiography as supplementary information to decide whether to perform a bronchoscopy. The relatively low sensitivity of a chest radiograph in aspiration disease can be improved with computed tomography (CT) $\operatorname{scan}^{3}$. A negative result on bronchoscopy does not exclude foreign body aspiration. Proper chest physiotherapy with postural drainage and suction may be equally helpful as bronchoscopy.

\section{Acknowledgements}

We thank Dr. Ravi Dayasena, consultant ENT surgeon and Dr. Dayani Mendis, consultant anaesthetist of Lady Ridgeway Hospital for doing an emergency bronchoscopic examination; the medical officers, nurses and para medical staff of the operating theatre and the intensive care unit of Lady Ridgeway Hospital and Prof. R. Wijesundera, Head, Department of Botany, University of Colombo, for helping to identify the foreign body. 


\section{References}

1. Fitzpatrick P L, Guaris J L. Pediatric airway foreign bodies. Journal of Los Angeles State Medical Society 1998; 150(4): 138-41.

2. Sharma H S, Sharma S. Management of laryngeal foreign body in children. Journal of Accidental and Emergency Medicine 1999; 16(2): 150-3.

3. Franquet $\mathrm{T}$, Gimenez A, Roson N, Torrubia S, Sabate J M, Perez C. Aspiration disease: findings, pitfalls and differential diagnosis. Radiographics 2000; 20(3): 673-85.
4. De Silva G D I, Lamabadusuriya $\mathrm{S} P$, Abeywickrema R. Unresolving pneumonia in a child - look for an aspirated foreign body. The Ceylon Medical Journal 1996; 41(4): 159.

5. Oguz F, Citak A, Unuvar E, Sidal M. Airway foreign bodies in childhood. International Journal of Paediatric Otorhinolaryngology 2000; 52(5): 11 16.

6. Bessey E A. Morphology and Taxonomy of fungi. Hafner publishing company, New York 1968: 47780 . 
